\title{
Hubungan Multitasking Teknologi Informasi Terhadap Produktivitas Kerja (Studi Kasus: Mahasiswa ITS)
}

\author{
Galang Arga Marendha, Tony Dwi Susanto, dan Isrida Yul Arifiana \\ Jurusan Sistem Informasi, Fakultas Teknologi Informasi, Institut Teknologi Sepuluh Nopember (ITS) \\ Jl. Arief Rahman Hakim, Surabaya 60111 Indonesia \\ e-mail: tonydwisusanto@gmail.com, akukakiss@gmail.com, galang.marendha@gmail.com
}

\begin{abstract}
Abstrak-Pada era globalisasi saat ini cara hidup individu umumnya para remaja dan dewasa yang selalu bergerak cepat dalam mendapatkan informasi terbaru agar tidak tertinggal dari yang lain memungkinkan melakukan pekerjaan secara bersamaan. Mayoritas dari individu-individu menganggap melakukan banyak pekerjaan sekaligus dapat digunakan sebagai solusi yang tepat. Dengan kemajuan teknologi saat ini dan perilaku seperti itu, banyak sekali contoh pekerjaan yang dilakukan secara bersama-sama seperti halnya mengirim e-mail saat sedang menonton televisi maupun membuat laporan saat rapat. Teknologi informasi tersebut merupakan komponen yang mendukung peningkatan produktivitas kerja. Dalam hasil dari penelitian ini didapatkan perbandingan antara skenario 1 dengan 2 dan skenario 1 dengan 3 berpengaruh terhadap produktivitas kerja karena adanya penambahan tugas me-resume video dan mengerjakan 10 soal matematika, sedangkan perbandingan skenario 2 dengan skenario 3 didapatkan dari hasil wawancara terhadap responden bahwa tidak adanya pengaruh pada produktivitas kerja dikarenakan penambahan tugas me-resume video skenario 2 lebih sulit dari tugas me-resume video skenario 3 serta penambahan 10 soal matematika tidak menjadi masalah dalam pengerjaan skenario 3. Dalam hasil hubungan multitasking teknologi informasi skenario 1 didapatkan hasil 33,1\% terhadap produktivitas kerja, kemudian hubungan multitasking teknologi informasi skenario 2 didapatkan hasil $23,6 \%$ terhadap produktivitas kerja, dan hubungan multitasking teknologi informasi skenario 3 didapatkan hasil $24,8 \%$ terhadap produktivitas kerja. Sehingga dari pengerjaan skenario 2 dan 3 produktivitas kerja responden menurun dikarenakan adanya tambahan kuantitas pengerjaan.
\end{abstract}

Kata Kunci-Multitasking, Produktivitas Kerja, SPSS, Teknologi Informasi

\section{PENDAHULUAN}

$\mathrm{P}$ ERMASALAHAN yang terjadi saat ini pada adalah banyaknya pekerjaan dilakukan sekaligus disaat yang bersamaan. Cara hidup individu yang cepat agar tidak tertinggal memungkinkan untuk melakukan pekerjaan secara bersamaan [1]. Mayoritas individu menganggap melakukan banyak pekerjaan sekaligus dapat digunakan sebagai solusi yang baik untuk menyelesaikan pekerjaan tersebut. Mulai dari membuat laporan saat rapat, memeriksa email ketika menonton televisi, hal ini dilakukan semua orang agar semua pekerjaan dapat dikerjakan lebih efisien dari segi waktu. Melakukan pekerjaan yang banyak sekaligus merupakan istilah dari multitasking. Multitasking adalah melakukan dua atau lebih pekerjaan secara bersamaan. Dengan kemajuan teknologi informasi saat ini yang merupakan salah satu komponen pendukung peningkatan produktivitas kerja maka diperlukan penggunaan multitasking. Sehingga untuk mencapai produktivitas kerja yang tinggi serta efisien dalam satu waktu dengan memanfaatkan penggunaan multitasking tersebut [2]. Penggunaan multitasking ini memberikan perubahan terhadap individu dalam menghadapi berbagai tugas yang diberikan sehingga akan meningkatkan kualitas kerja dari individu, fleksibilitas kerja para individu mengalami peningkatan perkembangan serta respon terhadap perubahan teknologi yang baru meningkat [3]. Meskipun individu menganggap multitasking akan mempermudah dan mempercepat suatu pekerjaan, penelitian menemukan perpindahan ini dapat mengurangi kemampuan otak dalam mengambil informasi dari pekerjaan tersebut [4]. Selain itu, multitasking mengurangi kemampuan untuk berkonsentrasi untuk jangka waktu yang panjang dan meningkatkan waktu yang diperlukan untuk menyelesaikan pekerjaan yang diberikan, tetapi juga risiko membuat kesalahan [5]. Dari beberapa hal tersebut penulis mengambil penelitian tentang HUBUNGAN MULTITASKING TEKNOLOGI INFORMASI TERHADAP PRODUKTIVITAS KERJA. Dalam penelitian ini nantinya akan digunakan metode sample acak terhadap mahasiswa ITS. Setelah melakukan observasi, penulis akan melakukan analisis uji reliabilitas serta validitas dan uji regresi terhadap hipotesa untuk dapat mengetahui hubungan multitasking teknologi informasi pada produktivitas kerja individu.

\section{TINJAUAN PUSTAKA}

\section{A. Produktivitas Kerja}

Menurut Wignjosoebroto, produktivitas kerja ditentukan dua faktor penting yaitu: faktor teknis dan faktor manusia. Faktor teknis adalah faktor yang mempunyai hubungan dengan pemakaian dan penerapan fasilitas produksi dengan penerapan metode kerja yang lebih efektif dan efisien. Faktor manusia adalah faktor yang mempunyai pengaruh dari usaha-usaha yang dilakukan manusia untuk menyelesaikan pekerjaan. Dari dua faktor diatas akan menentukan kemampuan kerja dan motivasi kerja manusia untuk meningkatkan prestasi kerja [7]. Menurut Anoraga dan Suyati, produktivitas terbagi menjadi 3 konsep yang ekonomis, filosofis dan sistem. Dalam konsep ekonomis, 
produktivitas berhubungan dengan usaha manusia dalam menghasilkan barang serta jasa dalam memenuhi kebutuhan hidup pada umumnya. Dalam konsep filosofis, produktivitas mengandung pandangan hidup dan sikap mental yang berusaha untuk meningkatkan mutu kehidupan menjadi lebih baik dari sebelumnya. Dalam konsep sistem, produktivitas kerja memberikan suatu pemikiran dalam mencapai suatu tujuan harus selalu ada paduan dari unsur-unsur yang relevan sebagai sistem. Menurut De Greef menyebutkan ada delapan faktor yang mempengaruhi produktivitas, yaitu (1) physical working environment, (2) work methods, (3) investments, (4) salary basis, (5) fluency of works, (6) work content, (7) internal cooperation and development, dan (8) market situation of products. Berdasarkan 8 faktor diatas, penelitian tentang produktivitas kerja hanya meneliti mengenai faktor teknis dan faktor manusia yang mempengaruhi produktivitas kerja secara terpisah [7]. Hal ini bertujuan mengetahui pengukuran produktivitas kerja individu dalam penelitian ini.

\section{B. Multitasking}

Menurut Benbunan-Fich, ada 2 prinsip utama dalam multitasking yaitu tugas dan waktu. Sehingga dengan begitu multitasking dapat didefinisikan sebagai tugas-tugas yang dikerjakan dalam waktu yang bersamaan. Selain itu kehandalan melakukan multitasking sangat penting bagi individu dan organisasi, hal ini disebabkan kondisi yang sering terjadi dalam kehidupan sehari-hari. Multitasking didefinisikan sebagai beberapa tugas yang dikerjakan sekaligus dalam waktu yang sama. Multitasking sering dilakukan oleh individu karena dianggap lebih efisien daripada hanya berfokus pada tugas tunggal pada suatu waktu [5]. Menurut studi yang dilakukan Adcock, Constable, Gore dan Goldman-Rakic yang meneliti tentang kondisi gelombang otak dari 16 mahasiswa dalam pengerjaan tugas tunggal dan tugas ganda, mereka mengemukakan bahwa adanya aktivitas gelombang otak pada pengerjaan tugas ganda lebih bekerja lebih keras daripada saat mengerjakan tugas tunggal. dalam hal ini pengerjaan tugas ganda akan menjadikan manusia berpikir lebih kompleks dan rumit [4]. Alat media teknologi jika digunakan secara tepat akan meningkatkan pembelajaran siswa namun di sisi lain juga memberikan dampak yang buruk bagi pembelajaran siswa. Dalam hal ini Fried meneliti bahwa penggunaan laptop di dalam kelas akan membuat siswa menghabiskan waktu untuk melakukan multitasking. Penggunaan laptop didalam kelas akan mengalihkan siswa dari pembelajaran para pengajar, bahkan siswa-siswa tersebut berkecenderungan untuk membuka internet dan media sosial [4].

\section{Sampel Penelitian}

Pengambilan suatu data dapat menggunakan metode sampling (sampel) dengan sensus. Untuk sensus semua elemen harus di observasi dan hasilya berupa data yang sebenarnya, sedangkan untuk metode sampling dapat dilakukan hanya dengan mengobservasi sebagian elemen yang menghasilkan data perkiraan. Teknik sampling ini terbagi menjadi dua yaitu teknik probability sampling dan non probability sampling. Probability sampling bersifat objektif dan bisa diperkirakan hasilnya. Ada empat metode dari probability sampling untuk mendapatkan sampel yaitu simple random sampling, systematic random sampling, stratified random sampling, dan clustered random sampling. Sedangkan teknik non probability sampling bersifat subyektif dan tidak dapat diperkirakan hasilnya. Pada teknik non probability sampling ini juga mempunyai empat metode dalam mendapatkan sampel yaitu convenience sampling, purposive sampling, quota sampling dan snowball sampling [6].

\section{METODOLOGI}

\section{A. Metodologi Penelitian}

Bab ini berisi metodologi dalam pengerjaan tugas akhir. Urutan pengerjaan, definisi dari setiap proses dan tools yang digunakan. Metode penelitian diawali dari studi literatur, lalu dilanjutkan dengan penentuan dimensi dan subdimensi yang akan digunakan dalam evaluasi. Setelah itu, dilakukan pembuatan skenario yang diberikan kepada responden. Kemudian observasi dilakukan untuk mengumpulkan data yang kemudian akan divalidasi. Analisis dan penilaian akan dilakukan setelahnya. Kemudian hasil akhir dari penelitian ini akan menghasilkan sebuah laporan. Berikut ini merupakan metodologi dalam pengerjaan tugas akhir ini:

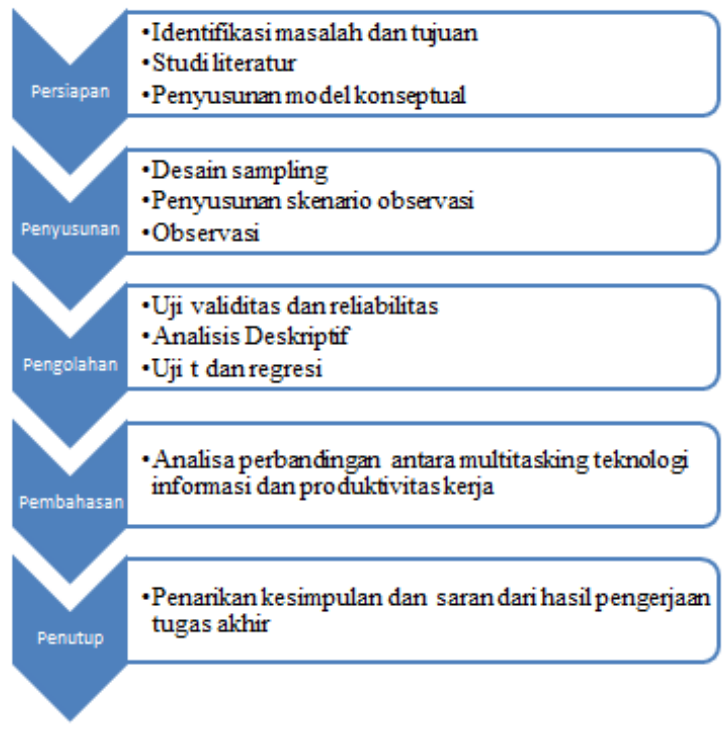

Gambar 1 Metodologi pengerjaan Tugas Akhir

\section{B. Identifikasi Permasalahan dan Tujuan}

Pada tahap ini mengidentifikasi permasalahan tentang pengaruh dari multitasking teknologi informasi terhadap produktivitas kerja. Dari permasalahan tersebut manusia berkecenderungan untuk mengerjakan tugas secara bersamasama demi menghasilkan beberapa tujuan tertentu. Di sisi lain hal itu sangat mempengaruhi produktivitas kerja manusia, karena produktivitas kerja manusia dapat dinilai maksimal jika kualitas dari kerja tersebut berbanding lurus dengan kuantitas kerjanya. Semakin sering manusia melakukan multitasking maka kuantitas pekerjaan tersebut dinilai kurang optimal [6].

\section{Penyusunan Model Konseptual}

Pada tahap ini penyusunan model konseptual berisitentang variabel-variabel multitasking serta indikator-indikator dari produktivitas kerja. Berikut ini gambaran model konseptual tentang penelitian ini: 


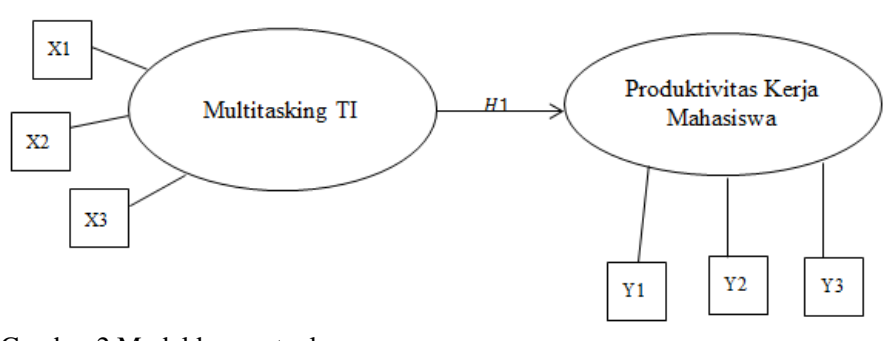

Gambar 2 Model konseptual

\section{Desain Sampling}

Pada tahap ini desain sampling yang digunakan adalah dengan menggunakan teknik purposive sampling. Hal ini digunakan untuk memenuhi kriteria peneliti dalam pengerjaan tugas akhir yang telah ditentukan. Penyusunan skenario observasi berdasarkan model konseptual yang telah dibuat sebelumnya. Observasi ini dinilai berdasarkan kuantitas, kualitas dan kecepatan kerja. Media yang digunakan dalam observasi ini adalah laptop dan browser internet. Berikut ini daftar skenario observasi penelitiannya:

Tabel 1

Daftar skenario observasi

\begin{tabular}{cl}
\hline \hline No & \multicolumn{1}{c}{ Skenario } \\
\hline 1 & Mengetik 450 kata di PC/komputer menggunakan Microsoft Word \\
2 & $\begin{array}{l}\text { Mengetik 450 kata di PC/komputer menggunakan Microsoft Word } \\
\text { dan melakukan resume video di Youtube }\end{array}$ \\
3 & $\begin{array}{l}\text { Mengetik 450 kata di PC/komputer menggunakan Microsoft Word, } \\
\text { melakukan resume video di Youtube dan mengerjakan 10 soal } \\
\text { matematika }\end{array}$ \\
\hline \hline
\end{tabular}

\section{PERANCANGAN}

\section{A. Penyusunan Skenario}

Penyusunan skenario ini berdasarkan variabel-variabel yang terdapat pada model konseptual, model tersebut memiliki 3 variabel dalam penelitiannya, yaitu: kuantitas kerja, kualitas kerja dan kecepatan kerja. Tabel 2 adalah daftar skala yang akan digunakan.

Tabel 2

Skala likert pernyataan

\begin{tabular}{clc}
\multicolumn{3}{c}{ Skala likert pernyataan } \\
\hline \hline No. & \multicolumn{1}{c}{ Pernyataan } & $\begin{array}{c}\text { Skor untuk } \\
\text { pernyataan }\end{array}$ \\
\hline 1. & Sangat Mampu (SS) & 5 \\
2. & Mampu (M) & 4 \\
3. & Normal (N) & 3 \\
4. & Tidak Mampu (KM) & 2 \\
5. & Sangat Tidak Mampu (STM) & 1 \\
\hline \hline
\end{tabular}

\section{B. Penentuan Responden Skenario}

Penentuan jumlah responden pada penelitian ini telah di jelaskan sebelumnya menggunakan mahasiswa ITS, yaitu sebanyak 100 orang.

\section{IMPLEMENTASI}

\section{A. Uji Validitas dan Uji Realibilitas Skenario 1}

Pada uji reliabilitas skenario 1 ini menjelaskan bahwa observasi dapat dikatakan reliabel karena nilai cronbach alpha dari masing-masing variabel telah lebih besar dari 0,6. Yaitu 0,75; 0,709;0,822.

Pada uji validitas skenario 1 ini didapatkan nilai pearson correlation-nya bernilai 0,632; 0,590; 0,780.

\section{B. Uji Validitas dan Uji Realibilitas Skenario 2}

Pada uji reliabilitas skenario 2 ini menjelaskan bahwa observasi dapat dikatakan reliabel karena nilai cronbach alpha dari masing-masing variabel telah lebih besar dari 0,6. Yaitu 0,969; 0,656; 0,607.

Pada uji validitas skenario 1 ini didapatkan nilai pearson correlation-nya bernilai 0,$940 ; 0,544 ; 0,458$.

\section{Uji Validitas dan Uji Realibilitas Skenario 3}

Pada uji reliabilitas skenario 3 ini menjelaskan bahwa observasi dapat dikatakan reliabel karena nilai cronbach alpha dari masing-masing variabel telah lebih besar dari 0,6. Yaitu 0,908; 0,776; 0,657.

Pada uji validitas skenario 3 ini didapatkan nilai pearson correlation-nya bernilai 0,$834 ; 0,636 ; 0,495$.

\section{Uji T}

Pengujian T (T Test) digunakan untuk menguji nilai rata-rata antar dua kelompok yang memiliki nilai berbeda. Pengujian T dilakukan pada skenario 1, 2 dan 3 .

Tabel 3

Uji T skenario 1 terhadap skenario 2

\begin{tabular}{lccccc}
\hline \multicolumn{1}{c}{ Skenario } & Mean & Lower & Upper & $t$ & sig \\
\hline $\begin{array}{l}\text { Skenario } \\
1\end{array}$ & & & & & \\
$\begin{array}{l}\text { Skenario } \\
2\end{array}$ & 2,57 & 2,44625 & 2,69375 & 41,206 & 0,000 \\
\hline \hline
\end{tabular}

Pada tabel di atas, merupakan hasil uji $\mathrm{T}$ antara skenario 1 dan skenario 2 pada observasi. Pada hasil mean, didapatkan nilai mean sebesar 2,57. Pada hasil uji T ini, peneliti mendefinisikan hipotesis sebagai berikut:

a. H0: Tidak adanya perbedaan rata-rata nilai dari skenario 1 dengan skenario 2

b. H1: Adanya perbedaan rata-rata nilai dari skenario 1 dengan skenario 2

Dari hasil diatas disebutkan bahwa nilai signifikansi 0,000 sehingga $\mathrm{H} 0$ ditolak yang artinya adanya perbedaan rata-rata nilai dari skenario 1 dan skenario 2 .

Tabel 4

Uji T skenario 1 terhadap skenario 3

\begin{tabular}{lccccc}
\hline \multicolumn{1}{c}{ Skenario } & Mean & Lower & Upper & $t$ & sig \\
\hline $\begin{array}{l}\text { Skenario } \\
1\end{array}$ & & & & & \\
$\begin{array}{l}\text { Skenario } \\
3\end{array}$ & 2,67 & 2,53755 & 2,80245 & 40,000 & 0,000 \\
\hline
\end{tabular}

$\overline{\text { Pada tabel di atas, merupakan hasil uji T antara skenario } 1 \text { dan }}$ skenario 3 pada observasi. Pada hasil mean, didapatkan nilai mean sebesar 2,67. Pada hasil uji T ini, peneliti mendefinisikan hipotesis sebagai berikut:

a. H0: Tidak adanya perbedaan rata-rata nilai dari skenario 1 dengan skenario 3

b. H1: Adanya perbedaan rata-rata nilai dari skenario 1 dengan skenario 3 
Dari hasil diatas disebutkan bahwa nilai signifikansi 0,000 sehingga $\mathrm{H} 0$ ditolak yang artinya adanya perbedaan rata-rata nilai dari skenario 1 dan skenario 3.

Tabel 5

Uji T skenario 2 terhadap skenario 3

\begin{tabular}{lccccc}
\hline \multicolumn{1}{c}{ Skenario } & Mean & Lower & Upper & $t$ & sig \\
\hline Skenario & & & & & \\
2 & 0,1 & $-0,07270$ & 0,27270 & 1,149 & 0,253 \\
Skenario & & & & & \\
3 & & & & & \\
\hline \hline
\end{tabular}

Pada tabel di atas, merupakan hasil uji $\mathrm{T}$ antara skenario 2 dan skenario 3 pada observasi. Pada hasil mean, didapatkan nilai mean sebesar 0,1 . Pada hasil uji $\mathrm{T}$ ini, peneliti mendefinisikan hipotesis sebagai berikut:

a. H0: Tidak adanya perbedaan rata-rata nilai dari skenario 2 dengan skenario 3

b. H1: Adanya perbedaan rata-rata nilai dari skenario 2 dengan skenario 3

Dari hasil diatas disebutkan bahwa nilai signifikansi 0,253 sehingga $\mathrm{H} 0$ diterima yang artinya tidak adanya perbedaan rata-rata nilai dari skenario 2 dan skenario 3 .

\section{E. Uji Regresi}

Berdasarkan tabel, angka $R$ Square adalah angka korelasi dari nilai observasi skenario 1 yang dikuadratkan atau sama dengan nilai $\mathrm{R} 0,575$, sehingga nilai yang didapatkan dari uji regresi tersebut adalah 0,331 . Nilai $R$ Square tersebut di persentasekan menjadi $33,1 \%$.

Tabel 6

Uji regresi skenario 1

\begin{tabular}{cccc}
\hline \hline $\mathrm{Uji}$ & $\mathrm{R}$ & $\mathrm{R}$ square & Adjusted $\mathrm{R}$ square \\
\cline { 2 - 4 } Regresi & 0,575 & 0,331 & 0,317 \\
\hline \hline
\end{tabular}

Berdasarkan tabel, angka $R$ Square adalah angka korelasi dari nilai observasi skenario 2 yang dikuadratkan atau sama dengan nilai $\mathrm{R} 0,486$, sehingga nilai yang didapatkan dari uji regresi tersebut adalah 0.236 . Nilai $R$ Square tersebut di persentasekan menjadi $23,6 \%$.

Tabel 7

Uji regresi skenario 2

\begin{tabular}{cccc}
\hline \hline Uji & $\mathrm{R}$ & $\mathrm{R}$ square & Adjusted $\mathrm{R}$ square \\
\cline { 2 - 4 } Regresi & 0,486 & 0,236 & 0,220 \\
\hline \hline
\end{tabular}

Berdasarkan tabel, angka $R$ Square adalah angka korelasi dari nilai observasi skenario 3 yang dikuadratkan atau sama dengan nilai $\mathrm{R} 0,498$, sehingga nilai yang didapatkan dari uji regresi tersebut adalah 0,248 . Nilai $R$ Square tersebut di persentasekan menjadi $24,8 \%$.

Tabel 8

Uji regresi skenario 3

\begin{tabular}{cccc}
\hline \hline Uji & $\mathrm{R}$ & $\mathrm{R}$ square & Adjusted $\mathrm{R}$ square \\
\cline { 2 - 4 } Regresi & 0,498 & 0,248 & 0,232 \\
\hline \hline
\end{tabular}

\section{HASIL DAN PEMBAHASAN}

\section{A. Uji T}

Pada uji $\mathrm{T}$ pada tabel 3 di atas berdasarkan nilai rata-rata dapat ditarik kesimpulan bahwa hasil pekerjaan skenario 1 memiliki perbedaan dengan skenario 2 . Kemudian dengan hasil uji $\mathrm{T}$ yang signifikan pada angka 0,000 antara kedua nilai dapat ditarik kesimpulan bahwa skenario 1 mempunyai perbedaan dengan skenario 2 karena pada skenario 2 terdapat penambahan pekerjaan me-resume video.

Pada uji $\mathrm{T}$ pada tabel 4 diatas berdasarkan nilai rata-rata dapat ditarik kesimpulan bahwa hasil pekerjaan pekerjaan skenario 1 memiliki perbedaan dengan skenario 3 . Kemudian dengan hasil uji $\mathrm{T}$ yang signifikan pada angka 0,000 antara kedua nilai dapat ditarik kesimpulan bahwa skenario 1 mempunyai perbedaan dengan skenario 3 karena pada skenario 3 terdapat penambahan pekerjaan me-resume video dan mengerjakan 10 soal matematika.

Pada uji $\mathrm{T}$ pada tabel 5 diatas berdasarkan nilai rata-rata dapat ditarik kesimpulan bahwa hasil pekerjaan pekerjaan skenario 2 tidak memiliki perbedaan dengan skenario 3. Karena hasil uji $\mathrm{T}$ tidak signifikan dibawah angka 0,05 antara kedua nilai kemudian dapat ditarik kesimpulan bahwa skenario 2 tidak mempunyai perbedaan dengan skenario 3 . Hal tersebut dikarenakan video pada skenario 2 lebih mudah dipahami atau di-resume oleh responden daripada video pada skenario 3. Pada skenario 3 , adanya 10 soal matematika tidak berpengaruh pada responden dalam mengerjakan pekerjaan sehingga dapat ditarik kesimpulan skenario 2 dan 3 mempunyai bobot yang sama dalam melakukan pekerjaannya.

\section{B. Uji Regresi}

Berdasarkan hasil penelitian di atas, dapat ditarik kesimpulan bahwa skenario 1 yang terdiri dari variabel kuantitas, kualitas dan kecepatan kerja mempunyai korelasi yang kuat dan signifikan terhadap produktivitas kerja serta berpengaruh sebesar 33,1\% terhadap responden penelitian ini. Sehingga hipotesis yang didapat adalah H1: Adanya pengaruh antara multitasking teknologi informasi dengan produktivitas pada skenario 1 diterima.

Berdasarkan hasil penelitian di atas, dapat ditarik kesimpulan bahwa skenario 2 yang terdiri dari variabel kuantitas, kualitas dan kecepatan kerja mempunyai korelasi yang kuat dan signifikan terhadap produktivitas kerja serta berpengaruh sebesar 23,6\% terhadap responden penelitian ini. Sehingga hipotesis yang didapat adalah H1: Adanya pengaruh antara multitasking teknologi informasi dengan produktivitas pada skenario 2 diterima.

Berdasarkan hasil penelitian di atas, dapat ditarik kesimpulan bahwa skenario 2 yang terdiri dari variabel kuantitas, kualitas dan kecepatan kerja mempunyai korelasi yang kuat dan signifikan terhadap produktivitas kerja serta berpengaruh sebesar 23,6\% terhadap responden penelitian ini. Sehingga hipotesis yang didapat adalah H1: Adanya pengaruh antara multitasking teknologi informasi dengan produktivitas pada skenario 2 diterima.

\section{KESIMPULAN DAN SARAN}

\section{A. Kesimpulan}

Berdasarkan hasil penelitian yang telah dilakukan, maka didapatkan beberapa kesimpulan yaitu sebagai berikut:

1. Berdasarkan penelitian ini pengukuran produktivitas kerja individu dalam melakukan multitasking adalah pengukuran kuantitas, pengukuran kualitas dan pengukuran kecepatan kerja. Pengukuran kuantitas disini 
merupakan banyaknya pekerjaan yang dilakukan individu. Untuk pengukuran kualitas merupakan nilai yang dicapai individu. Sedangkan kecepatan kerja merupakan seberapa cepat dalam menyelesaikan sebuah pekerjaan.

2. Berdasarkan penelitian ini menunjukkan individu saat mengerjakan pekerjaan dengan melakukan multitasking dapat memberikan hasil yang berbeda-beda terhadap produktivitas kerja setiap individu.

3. Berdasarkan penelitian ini menunjukkan multitasking yang berpengaruh pada produktivitas kerja adalah faktor kuantitas kerja. Dengan penambahan pekerjaan akan menurunkan hasil kualitas dan kecepatan kerja pekerjaan yang dilakukan individu.

\section{B. Saran}

Dalam pengerjaan tugas akhir ini, terdapat hal-hal yang dapat dikembangkan lagi dalam penelitian selanjutnya, berikut:

1. Penelitian ini hanya mengambil responden dari mahasiswa laki-laki dan perempuan ITS. Sehingga peneliti menyarankan penelitian selanjutnya memilih lingkup populasi yang lebih besar agar tingkat produktivitas kerja nya tidak hanya dalam lingkup mahasiswa.

2. Pada penelitian ini didapatkan persentase pengaruh multitasking teknologi informasi terhadap produktivitas kerja yang masing-masing pada tiap skenario atau pekerjaan $33,1 \%, 23,6 \%$, dan $24,8 \%$ yang berarti masih terdapat $66,9 \%, 76,4 \%$ dan $75,2 \%$ variabel yang belum tercakup pada penelitian ini, sehingga perlu ada penelitian lanjut dalam mengetahui variabel-variabel tersebut.

\section{DAFTAR PUSTAKA}

[1] Christine Rosen, "The Myth of Multitasking," A Journal of Technology \& Society, p. 6, 2008.

[2] Katie R. Wahl, Christophe C. Lefort, Wyatt H. P. Frei Susannah C. Otto, "Exploring the Impact of Multitasking In the Workplace," Journal of Business Studies Quarterly, vol. 3, no. 4, pp. 154-162, 2012.

[3] Adam Marchionni Steven H. Appelbaum, "The multi-tasking paradox: perceptions, problems and strategies," Management Decisions, vol. 46, no. 9, pp. 1313-1325, 2008.

[4] Yvonne Ellis, Bobbie Daniels, and Andres Jauregui, "The Effect of Multitasking on The Grade Performance of Business," Research in Higher Education Journal, p. 10, 2010.

[5] R.F Adler and Raquel Benbunan-Fich, "Juggling on a high wire: Multitasking effects on performance," International Journal of HumanComputer studies, vol. 70, pp. 156-168, 2012.

[6] Nurhayati, "STUDI PERBANDINGAN METODE SAMPLING ANTARA SIMPLE RANDOM DENGAN STRATIFIED RANDOM," Jurnal Basis Data, vol. III, pp. 1-15, May 2008.

[7] I Putu Artama Wiguna, Yusroniya Eka Putri Rachman Waliulu Andri Adriadi Firman, "Pengaruh Karakteristik Individu Terhadap Prestasi Kerja Staf Perusahaan Konstruksi Dengan Metode Structural Equation Modelling (SEM)," Digital Library Repository ITS, pp. 1-6, July 2011. 